\title{
PATERNIDAD ADOLESCENTE: UNA CORRESPONSABILIDAD INVISIBILIZADA
}

\section{ADOLESCENT PATERNITY: AN INVISIBILIZED CORRESPONDENCE}

LILIANA MARIBEL JAYO SUQUILLO ${ }^{1}$

Recibido: 15 de mayo de 2017

Aceptado: 29 de agosto de 2017

\footnotetext{
${ }^{1}$ Pontificia Universidad Católica del Ecuador, Facultad de Psicología, Quito, Ecuador (ljayo@puce.edu.ec).
} 



\section{PATERNIDAD ADOLESCENTE: UNA CORRESPONSABILIDAD INVISIBILIZADA}

\section{ADOLESCENT PATERNITY: AN INVISIBILIZED CORRESPONDENCE}

Liliana Jayo S.

PALABRAS CLAVES: Paternidad, adolescencia, sexualidad, embarazo adolescente. KEY WORDS: Paternity, adolescence, sexuality, teenage pregnancy.

\section{RESUMEN}

El presente artículo consta de reflexiones derivadas de la investigación "Percepción de los adolescentes varones sobre la paternidad adolescente", realizada en el año 2014 en la ciudad de Quito, cuyos resultados fueron presentados en la Revista PUCE No. 100, publicada en el año 2015'. El planteamiento principal es que los discursos hegemónicos respecto de la adolescencia y de las sexualidades, convergen en la invisibilización de los padres adolescentes, produciendo efectos inadecuados en el manejo del tema del embarazo adolescente en distintos espacios; así en los ámbitos familiares, en las políticas públicas y programas, e incluso en el área de investigación.

\footnotetext{
${ }^{1}$ Barahona, P., Jayo, L., \& Puertas, R., (2015), “Percepción de los adolescentes varones sobre paternidad adolescente". Revista PUCE (ISSN 1390-7719), No. 100, páginas 33-54.
} 


\section{ABSTRACT}

The present article consists of reflections derived from the research "Perception of adolescent males about adolescent paternity", carried out in 2014 in the city of Quito, which results were presented in the Revista PUCE No. 100, published in 2015 . The main approach is that the hegemonic discourses regar- ding adolescence and sexualities, converge on the invisibilization of adolescent parents, producing inappropriate effects on the management of teenage pregnancy in different spaces; as well as in the family, in public policies and programs, and even in the area of research.

\section{INTRODUCCIÓN}

Generalmente se piensa en los hombres como sujetos que cometen violencias y en las mujeres como las víctimas de las mismas. Es poco usual que en el imaginario social se visibilicen los impactos que viven los hombres en la vida cotidiana, puesto que están naturalizados e inscritos en la subjetividad y en los cuerpos. Así por ejemplo el hecho que los hombres tienen que subir y bajar de los buses "al vuelo", es decir cuando están en movimiento, es significado como algo normal y parte de la vida de un hombre urbano. Esta"habilidad" debe ser alcanzada por los varones cuando se acercan a la adolescencia y suele ser interpretada como una demostración de hombría, por lo se constituye en algo propio de los hombres, sean estos adolescentes, jóvenes y adultos sobre todo. La "proeza de subir al vuelo", da cuenta de una forma de violencia cotidiana hacia los varones y permite entrever que la vigencia de representaciones sociales respecto de la masculinidad tradicional, que invisibilizan las afectaciones que viven los hombres.

El campo del embarazo adolescente no está exento de este imaginario social, al contrario, en él se destacan otros discursos sobre la adolescencia y la sexualidad, que se entretejen para reforzar la apreciación negativa sobre los adolescentes padres. En la investigación realizada sobre las percepciones de la paternidad adolescente en el año 2015, los varones entre 15 y 17 años residentes de la ciudad de Quito, indicaron que frente a un embarazo de su pareja, consideran que sí experimentarían un impacto significativo en sus vidas y que asumirían con responsabilidad su paternidad, tanto 
en la función de proveedor como en la de cuidador de su pareja e hijo/a². Si este dato resulta sorpresivo para el lector, ya es un indicador de lo que se busca problematizar en el presente artículo, cuyo objetivo es reflexionar sobre aquellos discursos que convergen y producen la invisibilización de la paternidad adolescente, en términos positivos.

\section{EL EMBARAZO ADOLESCENTE}

Cuando del embarazo adolescente se trata, está el componente que alude a las representaciones sociales sobre la adolescencia y la sexualidad, que tienden a ser negativos. Por lo tanto, el "embarazo adolescente" se convierte en un tema que equivale a un doble problema, adquiriendo un matiz casi catastrófico. Si se realiza un ejercicio de asociación libre con las palabras embarazo adolescente, suelen presentarse imágenes mentales como una chica embarazada, una joven con un bebé en brazos, una adolescente irresponsable, inexperta, abatida, desconsolada, triste, culpable, con vergüenza y tal vez miedo. En fin, una mujer "fracasada" y que saboteó su futuro. ¿Por qué no hay cabida para imágenes de mujeres adolescentes con ilusión, con alegría, con fortaleza entre otras? Es más, ¿por qué priman las imágenes de un sujeto femenino como protagonista y única responsable del emba- razo? ¿Dónde están los varones padres? ¿Por qué no hay imágenes mentales de adolescentes que dejaron sus estudios para trabajar, o de otros que combinan sus estudios con el trabajo, la mayoría de veces precario? ¿Imágenes de jóvenes que no tienen poder de decisión con respecto de su hijo o hija; de chicos que son privados de continuar con su relación de pareja y que en muchos casos reciben amenazas y el dictamen de no acercarse a su hijo, hija y/o pareja, por parte de sus propios padres o los de su pareja? Incluso, ¿por qué no aparecen imágenes de varones también alegres, con esperanzas e ilusiones, con orgullo, motivados, con la voluntad de tener un rol activo como padres, por lo tanto con un sentido de responsabilidad?

Cuando se conocen datos como los del informe del UNFPA publicado en el 2013, que indica que son más de 7 millones de adolescentes que se

\footnotetext{
${ }^{2}$ Barahona, P., Jayo, L., \& Puertas, R., (2015), “Percepción de los adolescentes varones sobre paternidad adolescente". Revista PUCE (ISSN 1390-7719), No. 100, páginas 33-54.
} 
convierten en madres al año ${ }^{3}$, que hay 70000 menores que mueren por complicaciones en el embarazo y parto, que 3,2 millones arriesgan su vida en abortos en condiciones no adecuadas y que además los embarazos son el resultado de la "ausencia de elección y de circunstancias ajenas a su voluntad" (El Comercio, 2013), cualquier persona se estremece por el oscuro panorama. Pero considerar solo estos datos, es negar que existen diversas formas de experimentar los embarazos y que para algunas y algunos adolescen- tes, no representa necesariamente un problema. De allí la pertinencia a revisar la intersección de las construcciones sociales en relación con la adolescencia, la sexualidad (feminidad, la masculinidad, las relaciones genéricas, los atributos, roles y estereotipos de género), el machismo, el marianismo y el patriarcado, así como su conjunción con la paternidad adolescente, palabras no tan populares como las de maternidad adolescente o su equivalente en el imaginario social, el embarazo adolescente.

\section{INTERSECCIÓN DE LA SEXUALIDAD Y ADOLESCENCIA}

Hablar de embarazo adolescente conduce a necesidad de repensar, de reflexionar sobre la sexualidad y la adolescencia. Respecto de la sexualidad, cabe mostrar características fundamentales, así: La sexualidad debe ser entendida como una construcción social, es decir que es configurada por la sociedad y que está ligada a las relaciones sociales, a los deseos, a los afectos y las emociones, a la vida integral, al contexto, y que por supuesto tiene un lugar, que es el cuerpo. Por lo tanto es fundamental cuestionar y deponer la noción de la sexualidad como natural, irresistible, incontrolable, instintual y hasta peligrosa (Weeks, s/a).
Según la OMS/OPS (2006), la sexualidad es "un aspecto central del ser humano, presente a lo largo de su vida. Abarca al sexo, las identidades y los papeles de género, el erotismo, el placer, la intimidad, la reproducción y la orientación sexual. Se vivencia y se expresa a través de pensamientos, fantasías, deseos, creencias, actitudes, valores, conductas, prácticas, papeles y relaciones interpersonales. La sexualidad puede incluir todas estas dimensiones, no obstante, no todas ellas se vivencian o se expresan siempre. La sexualidad está influida por la interacción de factores biológicos, psicológicos, sociales, económi-

\footnotetext{
${ }^{3}$ Mayoritariamente en los países en desarrollo, pero también los países industrializados como Estados Unidos.
} 
cos, políticos, culturales, éticos, legales, históricos, religiosos y espirituales". Es decir, la sexualidad atraviesa la vida misma y posee múltiples aspectos. Sin embargo, en el caso ecuatoriano la sociedad está plagada de prejuicios y discursos que la determinan como algo netamente biológico, que se debe ocultar, controlar y que incluso puede ser pecaminoso. Apreciación propia del mundo occidental, contrapuesto a miradas ancestrales de la sexualidad como parte de la cotidianidad, como fuente de bienestar e incluso relacionado con la espiritualidad. Es así que Gómez (2013) sostiene que la sexualidad en el caso de occidente, ha estado fuertemente influenciada por una moral sexual dominante que la reprime y condena.

Costales (2011) en su investigación sobre la educación sexual en Ecuador, identifica que existen discursos que refuerzan la naturalización y perspectiva moralista de la sexualidad, predominando tres tipos de discursos: el biológico, el médico y el ascético o moralista. Discursos que forman un entramado y que desde una mirada crítica deberían ser cuestionados, pues dibujan a la sexualidad en términos del buen funcionamiento del cuerpo, del riesgo de infecciones de transmisión sexual, del VIH/SIDA, del embarazo adolescente e incluso del "buen cauce" del comportamiento. Asimismo, se puede interrogar el hecho que se supone que Ecuador es un Estado laico, por lo tanto ¿no debería estar desprovisto de influencias que producen los discursos religiosos? Mideros (s/a) en su estudio realizado en la ciudad de Quito sobre sexualidad y embarazo adolescente, también expone aspectos en común.

Una de las formas de mirar el embarazo adolescente ha sido biomédica, cuyo eje central sería el enfoque de riesgo; que ubica en la población adolescente una serie de condiciones, prácticamente su propia naturaleza, especialmente vulnerables, muy particularmente fuente al ejercicio de sus sexualidad, la cual resulta altamente peligrosa (Mideros, s/a).

Lo referido confirma de la ausencia de discursos en el ámbito de la sexualidad que den cuenta de lo placentero, de lo lúdico, de las ternuras, de tantos afectos que se ponen en movimiento cuando de sexualidad se trata. Gómez (2013) refiere que la sexualidad es una forma de estar en este mundo, en tanto se es sujeto sexuado, por lo tanto es un componente determinante en la identidad. En consecuencia, si la sexualidad es tan fundamentalmente en la vida humana, es un reto darle el trato adecuado, con perspectivas amplias y no reduccionistas y deterministas. 
Si la sexualidad es mirada negativamente, ¿qué sucede cuando coincide en el tiempo de la adolescencia? La respuesta es sencilla, es doblemente satanizada, debido a que la adolescencia también es significada principalmente como problemática. La adolescencia también es una construcción social, pero es comprendida como una etapa altamente conflictiva, con predominancia del componente biológico, por lo tanto de la madurez sexual y reproductiva. La adolescencia es establecida como algo de lo que se adolece, es decir es significada en término de padecimiento y en consecuencia como una condición vulnerable. Es decir, hay discursos respecto de la adolescencia que dan cuenta de marcas negativas que la sociedad imprime en la población referida. Mideros (s/a) expone que "la imagen social de los y las jóvenes más difundida, parecería ser la que relaciona a chicos y chicas directamente con una serie de problemáticas" como alcohol, drogas, pandillerismo, entre otras muchas; y por supuesto el tema que nos interesa el embarazo adolescente. Aunque vale recalcar que ninguno de estos problemas sociales están presentes en forma exclusiva, ni son mayoritarios en las población en referencia".

La adolescencia no debería ser apreciada como un problema, así lo postuló ya la antropóloga Margaret Mead en 1930, en su estudio en Samoa, quien ex- puso que tratar a la adolescencia de esta forma, no era deseable, ni inevitable, ni necesaria (Mead, 1977 en Weeks, s/a: 59). En el caso ecuatoriano, a través de un estudio realizado por Ecuador Adolescente en el año 2006, se expone la necesidad de un giro conceptual importante de la noción de adolescencia hacia la de juventud, puesto que la adolescencia es considerada desde la negatividad (Carrier, 2007:19).

En cuanto al embarazo adolescente, convergen los discursos dominantes sobre la sexualidad y la adolescencia, producen las justificaciones para el control de los cuerpos adolescentes, los discursos sociales que culpabilizan y sancionan, y la noción dominante que el embarazo adolescente es un problema alarmante. Por supuesto, si existen realidades preocupantes asociadas al embarazo adolescente, primordialmente el que es resultado de la violencia sexual, y también la puesta en juego de la salud y vida de las madres, por los abortos espontáneos o provocados. Problemas no considerados prioritarios por el Estado y la sociedad, que dan cuenta de la puesta en riesgo y vulneración de los derechos humanos, específicamente de los sexuales y reproductivos. De allí la ausencia de políticas públicas y programas que contrarresten estos problemas, así principalmente la prevención del abuso sexual infantil y la despenalización del aborto. 
Como se puede notar, cuando se conjugan la sexualidad, la adolescencia y las representaciones sociales dominantes que se hacen de los hombres y de la paternidad, en nuestro contexto, surgen complejidades necesarias de revisar, cuestionar y aceptar.

\section{EMBARAZO ADOLESCENTE: "UNA CUESTION DE COLOR ROSA"}

Parece existir una feminización del embarazo adolescente como tal, es decir es apreciado, planteado y tratado como que fuese únicamente un asunto de mujeres. Esto se traduce en la información y cifras que solo hablan de mujeres y aspectos relacionados a ellas, tanto así que en los buscadores virtuales, la respuesta a la inserción de términos combinados como "paternidad adolescente", "varones y embarazo adolescente", "embarazo adolescente y hombres" entre otros, da como resultado el despliegue de páginas sobre pensiones alimenticias, consejos para padres de hijos adolescentes y también información variada sobre padres con hijas adolescentes embarazadas. Si se ofrece algún dato sobre paternidad adolescente, es el uso del término en forma genérica, por lo tanto se refieren únicamente a las mujeres. En fin, información virtual sobre el embarazo adolescente focalizado en lo femenino. Parecería entonces que la tendencia social dominante, es visibilizar solamente el impacto del embarazo adolescente en las mujeres, que por supuesto es un asunto serio por las implicaciones que pueden presentarse, pero que están determinadas por el entorno. Según Mideros (s/a), para el Estado, el embarazo adolescente es catalogado como una problemática de salud pública muy grave, pues estaría atentando a los planes de desarrollo perseguidos, más aún en países considerados como subdesarrollados o en vías de desarrollo. Por supuesto aquí se gestan además las políticas poblacionales, de higienización y natalistas, que responden a fuerzas de control dominantes, donde el interés por la anticoncepción y control de la natalidad se deben a las preocupaciones por el crecimiento de las poblaciones y el desarrollo de ciudadanos saludable y productivos. De allí, que en términos de Quintana (2010) se procura desde el Estado y sus instituciones "sexo seguro, cuerpos disciplinados", tal y como se titula su publicación.

A nivel de los espacios familiares y educativos, el tema del embarazo 
adolescente, suele ser planteado también como un tema propio de las mujeres, lo que es comprensible cuando se tienden argumentos que exponen a las mujeres como los sujetos que gestan en sus cuerpos, que paren y que corporalmente tienen la capacidad de alimentar. En consecuencia, el cuidado y la crianza materna, también se atribuye socialmente a la condición anatómica de una mujer, naturalizando así estos procesos. Chodorow (1984:13) plantea que el ejercicio maternal es un elemento universal y permanente de la división sexual del trabajo y que la vinculación con la capacidad de criar, lactar y cuidar al infante, es inevitable. Esta interpretación de la realidad, determina una focalización en las mujeres, desplazando y/o anulando a los progenitores varones, y las implicaciones propias del ejercicio de la paternidad. En la normativa social dominante aún se sostienen roles, atributos y estereotipos de género, que a veces parecen estar superados, pero que bajo una pausa y análisis, se concluye que no lo están.

Mijita, de gana compra esas pendejadas. Eso no funciona, lo que le va a pasar si sigue en esos caminos es que se va a quedar embarazada, y ahí ¡sí! Usted va a ver que su enamorado le va a dejar solita (Cruz, 2014. Archivo personal).
Las "pendejadas" son preservativos que una mujer de 21 años intentó comprar en una farmacia del Distrito Metropolitano de Quito, como parte de un ejercicio etnográfico para una clase. La actividad permite vivenciar el acceso a los métodos anticonceptivos e identificar los discursos sobre la sexualidad, anticoncepción, el género, la adolescencia, los derechos sexuales y reproductivos. Los resultados dan cuenta que a pesar que estamos en la era de la información, esta no es suficiente, puesto que se ponen en juego las actitudes respecto de la sexualidad y elementos fundamentales como el acceso a los métodos anticonceptivos. La compra de un preservativo por primera vez, evidencia sobremanera las dificultades propias y ajenas de contar con un medio que permita disfrutar de la sexualidad sin pensar siquiera en lo reproductivo. En todos los años que he propuesto el ejercicio, ningún joven ha recibido la respectiva felicitación por su sentido de responsabilidad y el ejercicio de sus derechos sexuales y reproductivos. Por lo tanto, la observación recibida por Cruz (2014), permite identificar que en la actualidad y en la cotidianidad de la sociedad ecuatoriana, hay una visión sobre los atributos y roles de género, normativizada y en dicotomía, que además se enredan con discursos machistas, marianistas, patriarcales. Asimismo, se puede analizar la tendencia a considerar a 
los adolescentes y jóvenes como sujetos irresponsables, que por su condición de hombres poseen una "naturaleza sexual incontrolable", explicando su búsqueda "urgente de sexo y nada más". Estos atributos hacen parte de las concepciones dominantes que se hacen respecto de los hombres "verdaderos", los que sumados a aspectos como la virilidad, la hombría y la fuerza, instalan en el imaginario social un ideal de la identidad masculina. A esto esta noción se la conoce como masculinidad hegemónica, que si bien existe, es apenas una de las tantas posibilidades de vivir las masculinidades.

...la masculinidad hegemónica expresa la existencia de un sistema de género donde unas formas de masculinidad son jerarquizadas y mejor valoradas que otras, instaurándose legítimamente como como norma en que lo masculino se ubica en posiciones de superioridad y dominación sobre lo no masculino (García, 2015).

Otro aspecto de la identidad masculina tradicional y dominante, es la ligazón que se le da al rol de proveedor. Rol que a más de dar cuenta de un característica también importante de la masculinidad hegemónica, también permite plantear el tema de la división dicotómica: esfera privada versus esfera pública, que permea la subjetividad y configura las relaciones entre los géneros masculino/femenino. La proyección de ejecutar el rol de proveedor, es el principal hallazgo que se encontró en la Investigación "Percepción de la Paternidad Adolescente, 2014", dando cuenta de las nociones establecidas en las relaciones de género. Respecto de lo público y privado, cabe manifestar que la noción de que las mujeres pertenecen a la esfera privada y consecuentemente los hombres a la esfera pública, es solo el resultado de la era de la industrialización, pues cabe recordar que antes de la misma tanto hombres como mujeres desarrollaban sus actividades de forma combinada en los hogares, dando como resultado la no asunción de actividades como propias de las mujeres u hombres. Es desde estos cambios sociales que tanto el ejercicio materno como paterno registran procesos de cambio, tratando de ajustarse a los tiempos modernos. Algo que no está exento de tensiones que impactan sus vidas, por tanto las relaciones de género también se ven afectadas.

El sistema de sexo/género que ha entrado en crisis es el que se estructuró a partir de la revolución industrial, con la separación del lugar de trabajo y la vida familiar (Jelin). Se comenzó a consolidar en el sector urbano de la región desde fines del siglo XIX y especialmente en las siete primeras 
décadas del siglo pasado. El orden social que entonces se pregonó trató de instaurar un tipo de familia distinta a la prevaleciente en la sociedad agraria y tradicional: la familiar nuclear patriarcal, donde el varón, como autoridad paterna y guía, preveía y dominaba sin contrapeso a la vida cotidiana, distinguía entre lo público y lo privado - el trabajo, la política y la calle para los hombres y la crianza, acompañamiento de los hijos y cuidado del hogar para las mujeres-, y establecía la división sexual de trabajo- los hombres en la producción y las mujeres en la reproducción (Olavarría, 2003:92).

Como efecto de estos "nuevos" procesos, se inicia el cuestionamiento y la reflexión sobre la diferencia sexual, dando como resultado el aparecimiento de los estudios de género pero focalizados en las mujeres. Posteriormente se inician los estudios en el campo de las masculinidades $^{4}$, marco que cobija el interés y las investigaciones sobre las situaciones y problemáticas que viven los hombres. En el caso de América Latina, es en la época a finales de los noventa que empieza a visibilizarse importantes y numerosos estudios sobre masculinidades, donde "los ejes temáticos abordados han sido la construcción de la identidad masculina, la paternidad, los ámbitos de homosocialidad masculina y salud reproductiva versus la sexualidad masculina" (Hernández, 2007). El tema de la paternidad, sus significados y dificultades, ha sido estudiado en países como Colombia, Chile, Brasil, México y Perú; sin embargo, en el tema de paternidad adolescente como lo señala Viveros (en Fuller, 2000), existe un "muro de silencio" a nivel de instituciones y personas involucradas en la paternidad adolescente, así como en investigaciones y bibliografía. Silencio traducido en la carencia de estudios de la paternidad adolescente no planificada, de cifras, de los significados e impactos en torno a la paternidad. Será acaso que este silencio es de alguna forma el

\footnotetext{
${ }^{4}$ En las ciencias sociales, el género se ha convertido en un campo especializado; un campo que primero permanece restringido al estudio de las mujeres, y a partir de los años 80 del siglo recién abandonado, se amplía con la problemática de la masculinidad, desarrollada principalmente en los países anglosajones (EE.UU., Australia, Canadá y Reino Unido) bajo el nombre de Men's studies. Es decir que, después de un primer momento en que se consideró que la mujer era la gran desconocida de la humanidad, por lo que se decidió hacer frente a esa situación de olvido investigando sobre ella, se pasó a considerar que el hombre, en contra de lo que se creía, era también -como rememora Badinter (1993)- otro desconocido. Sobre todo porque, cuando se hablaba sobre él, se le estaba sobre identificando a partir de un solo modelo de hombre, se estaba acudiendo explícita o implícitamente a una sola concepción del mismo (la del hombre patriarcal) (Jóciles, 2001).
} 
equivalente actual, de la creencia "llorar no es cosa de hombres". Creencia que se considera hoy en día superada, por la "obviedad" que implica, pero que parece haber adoptado otras formas; una de estas es el no reconocimiento de la posibilidad de un rol activo positivo sobre la paternidad en general y peor aún sobre la paternidad adolescente.

Jorge Luis Cardoso (1998), (...) sostiene que este silencio que rodea la paternidad adolescente implica una relación perversa de la sociedad con el adolescente. Al anular socialmente este tipo de paternidad, se acaba por legitimar la ausencia paterna pues se le dificulta al adolescente la posibilidad de pensar, prevenir o asumir su condición de padre real o virtual. Se concluye planteando que la atribución cultural de la concepción y crianza de los hijos a las mujeres determina que estos sean percibidos en la sociedad brasileña como seres pertenecientes a la madre y que el adolescente sea considerado únicamente como hijo y nunca como padre potencial (Viveros, en Fuller, 2000: 107).

Lo referido, permite señalar que en el tema del embarazo adolescente no solo es necesario sino pertinente, adoptar una perspectiva de género. Se entiende por género, no el sinónimo de la palabra mujeres, sino como una categoría de análisis que permite dar cuenta de las tensiones y necesidades que viven las mujeres adolescentes y también los varones adolescentes, en el caso del tema que se desarrolla. Unicamente de esta manera se puede trabajar en función de transformaciones socioculturales que garanticen una verdadera equidad entre los géneros, que se traduzca en la vida cotidiana de hombres y mujeres.

\section{LA PATERNIDAD Y LA (S) MASCULINIDADE $(S)^{5}$}

Se cree que la clave de la crisis del sistema sexo/género está en la revolución industrial, donde se escindió la vida familiar del lugar de trabajo. De esta manera el nuevo orden social influyó en la construcción de un nuevo tipo de familia, la nuclear patriarcal, en la que el hombre "como autoridad paterna y

\footnotetext{
${ }^{5}$ Los Men's studies, sin embargo, van a plantear que no existe la masculinidad, en singular, sino múltiples masculinidades, que las concepciones y las prácticas sociales en torno a la masculinidad varían según los tiempos y lugares, que no hay un modelo universal y permanente de la masculinidad válido para cualquier espacio o para cualquier momento (Jóciles, 2001).
} 
guía, proveía y dominaba sin contrapeso la vida cotidiana, distinguía ente lo público y lo privado- el trabajo, la política y la calle para los hombres y la crianza, acompañamiento de los hijos y cuidado del hogar para las mujeres-, y establecía la división sexual del trabajo - los hombres en la producción y las mujeres en la reproducción" (Fuller, 2000:s/n). Es aquí donde se puede identificar una nueva forma de masculinidad dominante, por ende una nueva forma de subjetividad que determina la configuración de la identidad masculina y de la paternidad.

Según Olavarría (2003) los estudios dan cuenta que en Suramérica hay una noción de masculinidad dominante o hegemónica incorporada en la subjetividad de hombres y mujeres. Este modelo de masculinidad sería parte de las identidades y regularía las relaciones de género, y además estaría causando tensión, frustración y dolor tanto en hombres como en mujeres; porque no hay correspondencia con la cotidianidad. La paternidad insertada en la identidad masculina hegemónica sería entendida como la capacidad de manuten- ción del hijo/a y de la pareja, y además la evidencia fehaciente que se goza de virilidad. Sin embargo, Kimmel (1997:49 en Jóciles, 2001; s/n) da cuenta que la "La virilidad no es estática ni atemporal, es histórica; no es la manifestación de una esencia interior, es construida socialmente; no sube a la conciencia desde nuestros componentes biológicos; es creada en la cultura. La virilidad significa cosas diferentes en diferentes épocas para diferentes personas". Es así, como las diversas realidades, temporalidades y contextos, asegurarían que no solo exista una masculinidad hegemónica, sino que haya una multiplicidad de masculinidades, provocando el resquebrajamiento de aquella masculinidad dominante, por tanto de aquel modelo paterno hegemónico también. Hay importantes investigaciones que han permitido conocer que la paternidad es una dimensión que fundamenta la vida de los hombres, que tiene una valoración positiva, que marca la vida, que significa la inauguración de un nuevo rol, generalmente ligado a la responsabilidad, por tanto el ingreso al mundo adulto 6 .

\footnotetext{
${ }^{6}$... los resultados en las investigaciones presentadas en esta conferencia muestran que, sin bien existen grandes diferencias en las prácticas, la paternidad ideal se define en los mismos términos. El padre es aquel que protege, provee, forma y educa. En términos de la identidad masculina, punto de partida de estas investigaciones, la paternidad es un eje central de la masculinidad. Esta se vive como el momento en que se cierra la etapa juvenil, significa un reordenamiento en la vida del varón y su inserción a un nuevo período en el que obtienen pleno reconocimiento social, es el punto en que un varón se convierte en un adulto. Es así que generalmente la paternidad va de la mano con la inserción en el espacio laboral. La inserción o no inserción laboral del padre abre, entonces, toda una serie de estrategias y de problemas de cara a la
} 
Estas formas de concebir la paternidad, fuera del marco de la visión social hegemónica, atentan contra aquel orden social establecido, lo que causa que sea invisibilizado todo aquello que no quepa en este marco dominante, donde las nociones giran en torno a los atributos, roles y estereotipos de género, que operarían así: los hombres son fuertes por lo tanto insensibles, tienen una sexualidad que se desborda y poco control sobre sus impulsos, por lo tanto son irresponsables, y en caso de ser padres, su rol básico podría ser el de la manutención. Concepciones como estas se traducen en la idea tan común que si una mujer adolescente se embarazo ha fracasado y que tendrá que asumir su maternidad con sufrimiento y además sola en términos de pareja y en algunos casos de su familia propia. Este dictamen social tan devastador en una adolescente embarazada, ¿cómo se traduce en el caso de los adolescentes varones?

Los varones primero por su identidad sexo-genérica ya estarían configurados como sujetos sin mayor control sobre sus impulsos, por lo tanto si "dejaron"a alguna mujer embarazada ("que en el mejor de los casos" sería su novia") no sería su responsabilidad, pues esta cualidad es propia de las mujeres, en cuanto a términos de la sexualidad. De allí el di- cho: "el hombre propone, la mujer dispone". Además, si hay una percepción sobre todo desde la familia que el joven en cuestión, es alguien tranquilo e incapaz de cometer tal irresponsabilidad; entonces no se dudará en pensar que seguramente el "pobre hombre" fue víctima de una "mala mujer", que se aprovechó de él y que, con seguridad, tiene otros intereses, como el económico. Incluso en el caso de confirmarse un embarazo, se cree que en los hombres surgiría la duda: ¿Será mío? Y si este cuestionamiento se supera, entonces el punto siguiente a resolver sería ¿Qué hacer? Si se sigue el orden de consideraciones de la visión social hegemónica sería: El chico niega que es su hijo/hija, el chico huye, el chico no decidirá responsabilizarse económicamente de su hijo/a (pues por su corta edad no tiene cómo ni con qué), el joven no aceptará, ni asumirá el rol paterno. En fin, el varón adolescente seguirá con su vida, a diferencia de la chica, a quien se le acabó la misma. Es poco probable desde esta mirada, pensar que un adolescente asumirá su paternidad de positiva, con alegría, con emoción, con esperanza, optimismo, con responsabilidad, con la predisposición a cambiar su vida para cumplir con el rol paterno y de pareja. Por supuesto esto puede estar acompañado de temores, angustias, ansiedades,

paternidad (Fuller, 2000: 28). 
como todo cambio que se presenta en la vida de todos los sujetos, incluso de los adultos.

En la vida por supuesto hay casos en los que pueden darse situaciones en las que los adolescentes padres no asumen su paternidad de forma responsable. Pero la pregunta es ¿por qué sucede esto? Las respuestas pueden llevarnos a tratar de contestar otro cuestionamiento: ¿Cuáles son los impactos que viven los adolescentes varones cuando van a ser o son padres? Por qué pensar que no tienen ningún impacto o que no son importantes en un embarazo adolescente, es evidenciar las nociones distorsionadas sobre lo masculino. Esto se evidencia en el extracto de una entrevista:

Cuando Alejandra me dijo "parece que estoy embarazada". Yo... iMe asusté, me quedé en blanco! Tenía 17 años y ella... juno menos que yo! Pero a la vez, sentí una emoción, que me causó una sonrisa porque me imaginé a aquel bebé, que era mío. Entonces pasaron mil pensamientos en mi cabeza: tengo que trabajar y así darle todo lo mejor a los dos.... mi novia y a mi hijo. Han pasado trece añotes! Ha sido difícil, pero también ha sido bonito. Tuve que estudiar y trabajar.... y jencima más! llegar a casa y cuidar de mi Paula, mi hija. Pero así logramos que su mamá tam- bién haga sus cosas y termine sus estudios. Yo claro que dejé de hacer cosas que se hace de jóvenes, a veces esto me enojaba pero creo que era por la misma edad. Ahora ya estamos más grandes. Alejandra y yo sabemos que sin el apoyo de nuestras familias, otra sería nuestra historia y con seguridad no estaríamos juntos los tres (Quique, 2014 entrevista).

Si se realizan historias de vida y/o grupos focales a hombres que son o han sido padres adolescentes, se puede conocer respuestas del orden particular, que dan cuenta de sus miradas como parejas, como padres, como jóvenes, como hombres. Voces como la de Quique (2014), que dan cuenta que a pesar del orden social establecido, que exige el "performance" de una masculinidad hegemónica, las realidades son distintas, pues hay masculinidades y paternidades, tanto como hombres existen. Esto se evidencia en la Investigación sobre la Percepción de la Paternidad Adolescente (2014), pues en el acercamiento a los jóvenes se conoció sus deseos de asumir la paternidad. Es pertinente entonces, pensar en que tal vez el mundo de los adultos sabotea de algunas maneras sutiles o manifiestas, las intenciones y los hechos, que dan cuenta de la responsabilidad que albergan y ejecutan los padres adolescentes. 
En el hecho de traer al mundo a un nuevo ser, independientemente de la edad y del género del implicado, siempre habrá decisiones, reacciones y consecuencias de matices diversos, que no deben ser catalogadas dicotómicamente como positivas o negativas, pues existen los puntos medios, las ambivalencias... Por ello tal vez no sea adecuado hablar del impacto negativo del embarazo en la adolescencia, sino tratar el tema sin nociones sesgadas tanto en torno a los géneros y a sus relaciones, a las adolescencias y las sexualidades. O mejor aún, si se revisa el impacto del embarazo adolescente desde una perspectiva de género y sin utilizar los discursos hegemónicos, se generan espacios necesarios para la escucha de las vivencias y testimonios que dan cuenta de aspectos positivos en torno al ejercicio de la paternidad y maternidad adolescente?

\section{CONCLUSIONES}

La percepción social sobre el embarazo adolescente está estigmatizada desde la mirada adultocentrista y dominante de la sociedad, desde los discursos biomédicos y ascéticos sobre la sexualidad, y desde los hegemónicos respecto de la adolescencia. Estos discursos sumados a los que se construyen en torno al embarazo adolescente y las identidades masculinas y femeninas, dan como resultado el énfasis en la madre adolescente y a la vez, en la invisibilización de la paternidad adolescente. Esto explica la sorpresa que suscitan los hallazgos de la investigación acerca de las "Percepciones sobre la Paternidad Adolescente" (2014), donde se presenta que los adolescentes se consideran a sí mismos como sujetos responsables de sus actos, por lo tanto capaces de asumir el cambio que implicaría una paternidad adolescente, principalmente en el rol de proveedor y cuidador de su pareja e hijo/a. En consecuencia, si la disposición a la responsabilidad existe, posiblemente se ve afectada y también interrumpida, por los discursos que se entretejen para definir a un padre adolescente como un sujeto incapaz de responsabilizarse de sus actos, por lo tanto se edifican justificaciones para invisibilizarlo y tal vez hasta anularlo en su ejercicio paterno.

El embarazo adolescente por supuesto causa un impacto, pero este esta-

\footnotetext{
${ }^{7}$ En el presente artículo se descarta el tipo de embarazo, que resulta como producto del abuso sexual, puesto que ello merece otra lectura distinta, ya que se trata de un delito y de una violación a los derechos humanos fundamentales.
} 
ría sujeto al abordaje que se despliegue en el entorno de los adolescentes en cuestión. Por lo tanto, se hace imprescindible el contrarrestar la fijación en las cuestiones negativas y la negación de la existencia de aspectos positivos que se desprenden del ejercicio paterno como materno en el caso de los adolescentes.

Es pertinente atender la situación del embarazo adolescente desde una perspectiva de género, por lo tanto se deben incluir a los dos actores y no solo focalizarse en la mujer, puesto que esto contribuye a la manutención de la invisibilización del padre adolescente y porqué no decirlo, a la ausencia de la figura paterna en lo real, lo imaginario y lo simbólico en la vida de los niños y niñas. Solo de esta manera, se incidirá en la transformación de la mirada respecto del tema del embarazo adolescente, posibilitando un mayor bienestar en la vida tanto de las y los jóvenes adolescentes, como de sus hijas e hijos. 


\section{BIBLIOGRAFÎA}

Barahona, P., Jayo, L., \& Puertas, R., (2015), Percepción de los adolescentes varones sobre paternidad adolescente. Revista PUCE (ISSN 13907719), No. 100, páginas 33-54.

Carrier, A., (2007). Representaciones Sociales de los y las adolescentes del Ecuado". Sin publicación.

Chodorow, N., (1984). El ejercicio de la maternidad. España: Gedisa.

Costales, M. (2011). Sexualidad educada: discursos de educación sexual desde el colegio y el estado. FLACSO- ABYA YALA.

El Comercio (31 de octubre de 2013). Embarazo en adolescentes aumenta. EL COMERCIO, pág. www. elcomercio.com.ec

Jayo, L., (2014). Entrevista Quique. Archivo Personal.

Jayo, L., (2014). Informe etnográfic". Archivo Personal.

Fuller, N., (2000). Paternidades en América Latina, Perú: Fondo Editorial.

García, L. (2015). Nuevas masculinidades: discursos y prácticas de resitencia al patriarcado. Quito: FLACSO Sede Ecuador.
Gómez, J., (2014). Psicología de la Sexualidad, Madrid: Ed. Alianza.

Jóciles, M., (2001). El estudio sobre las masculinidades. Panorámica general. Gaceta de Antropología, 2001, 17, artículo $27 \cdot$ http://hdl. handle.net/10481/7487. Versión HTML · Versión PDF Publicado: 2001-11

Lamas, M. (s/a). El género: una categoría útil para el análisis histórico. Scott, 1996 en El Género: la construcción cultural de la diferencia sexual. PUEG, México.

Olavarría, José (2003). Los estudios sobre masculinidades en América Latina: Un punto de vista.

Organización Panamericana de la Salud (OPS/OMS). (2006). No Title. Washington D.C.

Quintana, M. Soledad (2010). "Sexo seguro, cuerpos disciplinados" Quito: FLACSO - Sede Ecuador: Abya Yala.

Weeks, J. (s/a). "La Invención de la Sexualidad"México: UNAM. 
